\title{
A NOVÍSSIMA LITERATURA PORTUGUESA: NOVAS IDENTIDADES DE ESCRITA ${ }^{1}$
}

Gabriela Silva ${ }^{2}$

\begin{abstract}
Resumo: À luz do que denominamos como contemporâneo, marcada pela necessidade de redescoberta do homem português, sua apreensão do real e posicionamento no mundo hodierno, são as principais características da literatura produzida em Portugal nos dias atuais. Associadas às diferentes formas de narrar e pensar a escrita Gonçalo M. Tavares, Nuno Camarneiro e Afonso Cruz, destacam-se entre os novos escritores portugueses. Rompem com a questão de narrar apenas dentro da identidade cultural a que estão associados, ao mesmo tempo alicerçam uma nova concepção do seu papel de inventor/criador de universos ficcionais. O espaço ficcional é por sua natureza o espaço das possibilidades.
\end{abstract}

Palavras-chave: narrativa; contemporaneidade; literatura portuguesa contemporânea; identidade.

\section{THE NEWEST PORTUGUESE LITERATURE: NEW WAYS OF THINKING CHARACTER'S IDENTITIES IN WRITING}

\begin{abstract}
In the light of what it's been recognized and accepted as contemporary, specifically concerning the Portuguese literature, there's is an urge to rediscover and redefine what one understands by the Portuguese being and his/her insertion in the actual world. Gonçalo M. Tavares, Nuno Camarneiro and Afonso Cruz, are among the newest and most talented Portuguese writers who have been associated with different forms of narrating and of thinking fiction and character development. The three of them have chosen to surpass the cultural and national identity to which they would be directly associated, and, at the same time, have set the basis for a new way of conceiving/creating fictional settings. The fictional world and space, is, by its own nature, the arena for the experimentation of new possibilities.
\end{abstract}

Keywords: narrative; contemporary; Portuguese contemporary literature; identity.

A literatura portuguesa tem contribuído de forma significativa na leitura do mundo em todas as épocas, colocando-se como umas literaturas mais lidas fora de seu país. Berço de grandes nomes como Luís de Camões, Eça de Queiroz, Fernando Pessoa, Vergílio Ferreira, Lídia Jorge e José Saramago entre tantos outros reconhecidos internacionalmente, a literatura produzida em Portugal é leitura e objeto de estudo em diversos lugares fora de seu âmbito de produção. Escritas marcadas pelo desejo de (re)escrita do passado, discursos históricos ficcionais e funcionais, preservadores e idealizadores da identidade são

\footnotetext{
${ }^{1}$ Ensaio resultante da pesquisa pós-doutoral realizado na Universidade de Lisboa, Faculdade de Letras, no Centro de Estudos Comparatistas, sob a supervisão da Professora Doutora Helena Carvalhão Buescu. O trabalho foi financiado pela Capes. Projeto apresentado em 2014 e executado em 2015/2016.

${ }^{2}$ Gabriela Silva é doutora em Letras - Teoria da Literatura pela Pontifícia Universidade Católica do Rio Grande do Sul.
} 


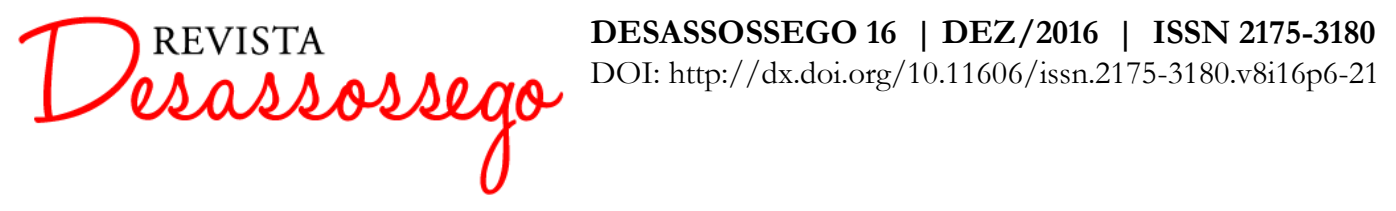

características que percorrem todas as épocas da literatura portuguesa, na afirmação de sua vOz como nação e arte.

Segundo Eduardo Lourenço,

Quer para o indivíduo, quer para o grupo, quer para uma nação, a identidade num sentido óbvio, é um pressuposto (...) para o indivíduo, o grupo, a nação, a questão de identidade é permanente e se confunde com a da sua mera experiência, a qual não é nunca puro dado, adquirido de uma vez por todas. Mas o ato de querer e poder permanecer conforme o ser ou ao projeto de ser aquilo que é. (2015, p. 9)

Essa necessidade que marca intensamente a literatura portuguesa perpassou diversas épocas históricas e tornou-se uma característica intrínseca de seus textos, quer poéticos, quer narrativos. A questão de sua origem, das guerras e personalidades que compõem esse imaginário sempre foram recorrentes e presentes na literatura até os mais recentes dias.

Assim, desde Camões e a tentativa de compor uma ideia mítica e também eternizar a nação portuguesa através de Os Lusiadas, passando por Fernando Pessoa e a necessidade emergente de inovar e descobrir um novo Portugal nas suas muitas formas de escrita e a relação de amor e tristeza com o nacional e a origem, até Saramago e a crítica à construção dessa identidade através de analogias e metáforas que analisavam e inferiam sobre a realidade política e a construção de um passado mítico e idealizado, Portugal sustentou-se imagética e literariamente sobre o que desejava ser: uma grande e mítica nação.

À luz do que denominamos como contemporâneo, marcada pela necessidade de redescoberta do homem português, sua apreensão do real e posicionamento no mundo hodierno, percebemos quais são as principais características da literatura produzida em Portugal nos dias atuais. Associadas às diferentes formas de narrar e pensar a escrita, Gonçalo M. Tavares, Nuno Camarneiro e Afonso Cruz destacam-se entre os novos escritores portugueses. As obras escolhidas estabelecem entre si aspectos e elementos de construção narrativa que compõem diferentes movimentos de criação, recepção e contribuição ao imaginário dos leitores do século XXI. E destacam-se como mantenedoras do fluxo criativo literário português, justificando por suas características a necessidade e aporte da pesquisa sobre o tema.

Perceber as transformações que acontecem na literatura produzida em Portugal contemporaneamente é dispor-se a entender as modificações que avançam sobre o homem português e sua cultura. As relações históricas não se esgotam, mas se modificam, alteram- 


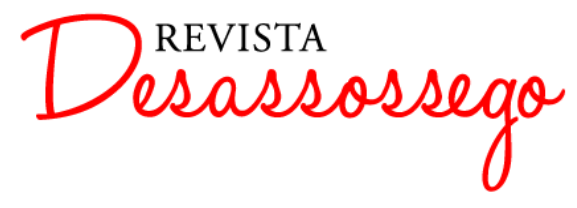

DESASSOSSEGO 16 | DEZ/2016 | ISSN 2175-3180

DOI: http://dx.doi.org/10.11606/issn.2175-3180.v8i16p6-21

se e expõem ao leitor um novo sujeito, com uma disposição anímica que vai além do espaço territorial que habita. Essa desnacionalização que acontece na literatura contemporânea portuguesa, deixando de lado um romance autenticamente centrado sobre os temas nacionais e que demarcavam uma cultura e uma literatura voltada sobre si mesma oferece ao homem português, esse novo sujeito que se abre ao mundo e se torna cosmopolita, uma nova configuração ideológica. O afastamento dessa história de um passado, quer distante, quer próximo e a expansão do horizonte dessa literatura demonstram esse sujeito que agora se dispõe a expandir-se identitariamente, percebendo também questões de alteridade e afastando-se do que as fronteiras territoriais e culturais impõem às sociedades e que de maneira singular se manifesta nas suas produções artísticas.

A ditadura salazarista, o fim das guerras coloniais e o regresso de residentes das antigas colônias (os chamados retornados) foram os impulsionadores de muitas narrativas contemporâneas, sob diversas nomenclaturas de tipos de escrita, essas ficções traziam para si o encargo de colocar ao mundo e aos próprios portugueses as vozes de sua especificidade identitária. Testemunhos de uma memória que não adormece. Sempre redimensionadas, as fronteiras entre a ficção e a realidade são características predominantes da literatura portuguesa.

Imagens e fatos que compuseram o imaginário português durante muitas décadas, expandindo e desdobrando-se em obras de diferentes configurações, Eduardo Lourenço comenta, em Labirinto da saudade, sobre Portugal "o seu lugar não se situa apenas no mapa e muito menos se circunscreve ao pequeno retângulo à beira do Atlântico, carregado de passado e vida singulares, que chamamos Portugal" (2015, p. 11). Assim, esse sujeito português passou a ocupar além dos seus limites fronteiriços e históricos, ele torna-se mais do que sua história e insere-se num contexto universal, de uma literatura sem demarcação ou delimitação, mas repleta da experiência humana de diferentes sujeitos em diferentes épocas. Então essa novíssima literatura portuguesa, se constrói sobre a perspectiva desse sujeito português que agora rompe com a tradição de temas e formas de construir personagens, tempo, espaço, enredo e narrador.

Se o espaço literário é o âmbito da representação do mundo a que pertencemos e o qual privilegiamos em nossas percepções, o universo mimético é então sempre renovado, numa maneira quase exaustiva de compor o quadro de nossa existência. Resgatam-se 


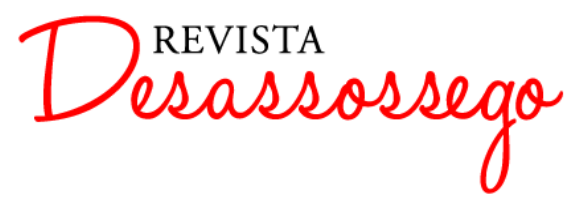

DESASSOSSEGO 16 | DEZ/2016 | ISSN 2175-3180

DOI: http://dx.doi.org/10.11606/issn.2175-3180.v8i16p6-21

aspectos históricos, discutem-se as questões literárias e de construção do texto, mas a existência e a contemplação do mundo serão sempre as linhas permanentes da literatura.

Ao pensarmos o contemporâneo, o atual, a sempre retomada história local, conjugando-a com a literatura, sua porta-voz, ou ainda mantenedora de diversas perspectivas ideológicas, perceberemos o quão forte isso foi na literatura portuguesa, principalmente se direcionarmos nosso olhar para Portugal a partir da década de 60 do século XX e as tendências do romance a começar desse momento histórico. Veremos a recorrente presença da liberdade política como objetivo, as demandas das classes sociais mais baixas, a configuração do estado e das estruturas políticas e também sociais e a relação do país com suas ex-colônias, como uma nova configuração ideológica e que também precisava renovar-se no imaginário português.

Como coloca Homi K. Bhabha em O local da cultura, o contemporâneo, o novo, representam uma ruptura com um determinado modo de pensar e trazem consigo diversas novas perspectivas. Essa "cisão" como ele denomina a ruptura, é um rompimento com a norma cotidiana, com o costume, com o de fato está arraigado e sustentando uma forma de pensar:

O novo e o contemporâneo aparecem através do ato de cisão da modernidade como acontecimento e enunciação, época e cotidiano. A modernidade como signo do presente emerge nesse processo de cisão, nesse lapso, que dá à prática da vida cotidiana sua consistência como contemporânea. É porque o presente tem o valor de um "signo" que a modernidade é interativa, um questionamento contínuo das condições da existência, tornando problemático seu pr6prio discurso não apenas "como ideias", mas como posição e status do locus do enunciado social. (BHABHA, 1998, p. 335)

A essa perspectiva social e urgente que se lança sobre a narrativa portuguesa, somam-se os experimentalismos ficcionais. Os recentes processos narrativos do português incluem não somente perspectivas do texto literário e da própria mimese como representação desse modo organizacional da sociedade portuguesa e mundial, mas uma forma diferente de ver o texto como o conjunto de fragmentos que se tornou o homem contemporâneo independente de sua nacionalidade. Ou seja, ela não deixa de ser resultado da reflexão do sujeito sobre sua permanência no mundo, mas essa literatura assume uma postura de percepção do que vai além da sua própria história. Para o mundo e do mundo, a novíssima literatura portuguesa abrange novas formas narrativas e também um novo 


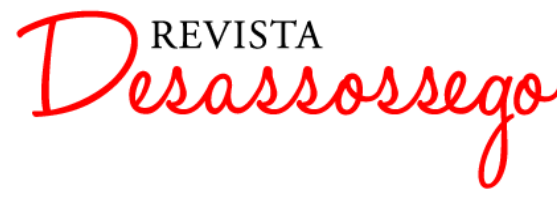

DESASSOSSEGO 16 | DEZ/2016 | ISSN 2175-3180

DOI: http://dx.doi.org/10.11606/issn.2175-3180.v8i16p6-21

discurso de identidade já enunciado e consolidado na história da literatura portuguesa e ocidental.

A literatura tem a potencialidade de ser memória cultural, de funcionar como o rastro que permite a identificação de formas de pensar e de viver dos homens de diferentes épocas, assim como sua reflexão sobre o mundo. Ela é experiência e permanência por relatar ou ainda, promover a leitura de determinados pontos de vista sobre a história, sobre o homem e sua relação com seu tempo, identidade e cultura. Em A literatura em perigo, Tveztan Todorov comenta dessas potencialidades da literatura, do que de fato ela pode realizar como instrumento da imaginação dos escritores e da recepção por parte dos leitores, assim pensar a literatura portuguesa ou determinada literatura é antes de tudo, pensar o que ela pode como espaço de manifestação de um imaginário, de uma cultura e de uma forma de pensar e ver o mundo:

A literatura pode muito. Ela pode nos estender a mão quando estamos profundamente deprimidos, nos tornar ainda mais próximo dos outros seres humanos que nos cercam, nos fazer compreender melhor o mundo e nos ajudar a viver. Não que ela seja antes de tudo uma técnica de cuidados com a alma porém revelação com o mundo, ela pode também, em seu percurso, nos transformar a cada um de nós a partir de dentro. (TODOROV, 2009, p. 76)

O passado, seja ele qual for, é material da escrita, mesmo que uma narrativa procure falar de possibilidade de futuro, sempre o passado, de uma determinada forma, surge na ficção como uma parte da elaboração do que se deseja projetar acerca do futuro. Passado e futuro são elementos indissociáveis na construção do que denominamos como presente e principalmente se pensarmos na construção de narrativas.

Antonio Cândido em Literatura e sociedade comenta do papel do escritor, da função social que é atribuída a ele e como a coletividade reconhece no escritor a figura de um dinamizador da cultura, da história. Em harmonia com o seu tempo, o escritor é um núcleo gerativo de uma possibilidade de visão social e cultural, também histórica e identitária.

Umberto Eco em Confissões de um jovem romancista comenta que a "narrativa é, para início de conversa, uma questão cosmológica", isso por que o autor para narrar assume a função de um demiurgo, de criador de um universo que deve ser o mais fiel possível ao mundo real e por onde esse autor possa andar em segurança. Pensando a partir do que nos diz Eco, escrever sobre algo que não está associado ao nosso contexto histórico ou ainda ao nosso cotidiano, entendido ou experienciado como patrimônio de nossa memória é 


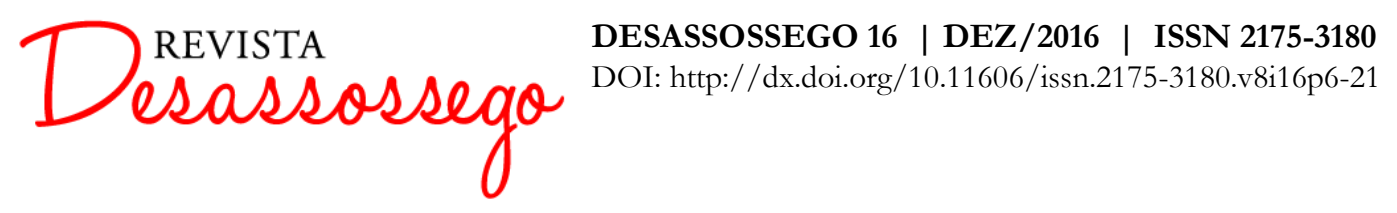

também ser um demiurgo de um mundo externo ao nosso, num rompimento de fronteiras que nos exige a capacidade de entender e assimilar o que é diferente e como esse diferente se compõe.

A escrita representa o desequilíbrio, uma determinada vontade de reajuste ou ainda uma necessidade de compreensão do mundo a que pertencemos. Uma obra literária é desse modo, resultado da relação do sujeito (escritor) com a realidade em que ele se insere e vive. Dentro desse contexto, podemos pensar a literatura como uma comunidade temática e afetiva, bem como uma comunidade de experiências formais, artísticas e de pensamento.

Pensar o mundo através de uma perspectiva de um português, vai além de pensar de uma maneira autóctone, mas um modo de leitura e apreensão das coisas e dos eventos. Essa determinada forma de percepção transforma-se em conexão com o mundo quando os temas e as narrativas desalojam-se do eixo territorial e histórico português. Saem de Portugal, expandem-se, ganham o mundo, ainda que escritos por portugueses e que muitas vezes personagens portuguesas componham as ações contadas. Já não é apenas a construção de uma identidade, de um sujeito num conjunto de situações específicas e que configuram demarcações identitárias e territoriais. É o que podemos definir como "literatura-mundo" a que se difunde, que deixa de ser uma experiência localizada, estanque, mas múltiplas, variantes, do mundo. Helena Carvalhão Buescu em Experiência do Incomum e boa vizinhança - Literatura comparada e Literatura-mundo define o que hoje nos permite perceber e entender o que essa literatura abrange: "A literatura mundo, ao pressupor uma ideia de presente que acolhe diferenciados momentos históricos, localizações geográficas e pertenças histórico-simbólicas, reforça por um lado o seu caráter intempestivo e, por outro, investe-o de uma capacidade política e simbólica que qualquer atualidade não pode ignorar."

Essa literatura-mundo é o que aqui nos interessa, ao descentralizarmos do âmbito português as obras literárias, em principal as produzidas por autores portugueses, ao escolhermos definir e entender essa produção contemporânea nos aliamos à definição de literatura-mundo que se aplica ao compartilhamento de experiências, de percepções de mundo, de existência, de situações históricas e sentimentais: “A literatura-mundo pode ser assim compreendida como uma experiência simultânea do comum e do incomum: arquivo de semelhanças potenciais, mas também de diferenças e infinitas variações." (BUESCU, 2013). 


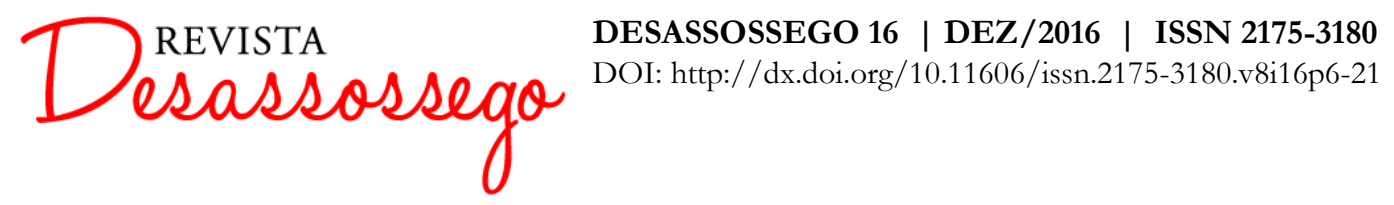

Para além de uma especificidade, de um território, é a leitura de um texto e a relação entre o que a literatura demanda como experiência e a origem de sua produção. A literatura então, além de comunicar ou exprimir, como afirma Roland Barthes em O gran zero da escrita, também expõe ao mundo uma determinada forma de um indivíduo perceber o seu tempo e a história a que pertence.

Assim, Gonçalo M. Tavares, Nuno Camarneiro e Afonso Cruz colocam-se como os autores portugueses contemporâneos reconhecidos como representantes de uma nova vertente literária, discursiva e de articulação sujeito-mundo. As narrativas desses autores singulares da literatura portuguesa do século XXI apresentam-se como a possibilidade da renovação do sentido do sujeito, não apenas o português, mas também ele no tempo e espaços contemporâneos.

A experimentação narrativa, a organização dos elementos intrínsecos ao texto literário, as diferentes formas de pensar e reagir ao mundo e as tentativas de revisão histórica são elementos constantes na literatura portuguesa.

Essa identidade portuguesa não aparece nessas narrativas como presença notória, mas o homem português como homem-mundo. "Pessoalmente, não quero investigar o homem-português, quero sim, perceber o homem, no geral e seus comportamentos", disse Gonçalo M. Tavares em entrevista à Editoral Caminho. Do mesmo modo Nuno Camarneiro e Afonso Cruz escrevem sobre o comportamento dos homens, sendo eles portugueses ou não. Num sempre movimento de rescrita do eu, das visões sobre o mundo. A busca dessa identidade é ficcionalizada e contextualizada em um universo ficcional que tenta sair do mapeamento português ${ }^{3}$.

As experiências narrativas, o estranhamento, a escrita que inova em seu conteúdo e técnicas singulares são os elementos que confirmam esses autores na contemporaneidade e justificam seu reconhecimento pela crítica através dos prêmios recebidos pelas suas obras.

Essas características que diferenciam as obras em seus aspectos constitutivos e também na direção de suas temáticas as colocam no mesmo foco de discussão e pesquisa: a novíssima literatura portuguesa. É, portanto, um olhar comparatista e por seu turno, analítico que aqui fazemos. No espaço ficcional, personagens, narradores, espaço e tempo configuram-se exercendo o papel de portadores das ideias desses autores sobre identidade.

\footnotetext{
${ }^{3}$ Já Saramago o fez em alguns livros, em que todas as referências localizadoras desapareceram, como acontece em Ensaio sobre a cegueira (1995) e em As intermitências da morte (2005).
} 


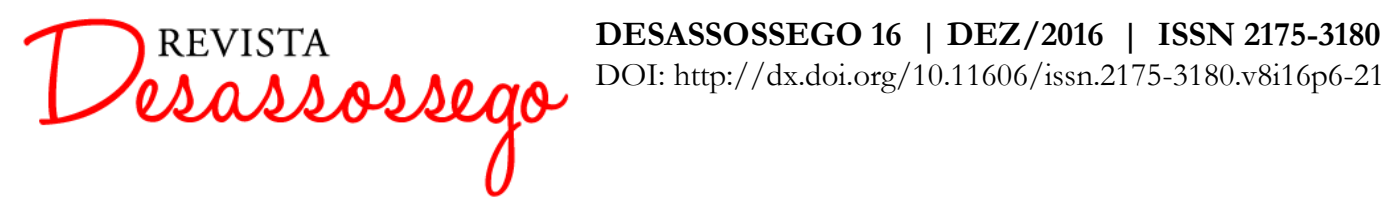

As relações de construção literária e percurso histórico estão intimamente ligadas. As obras são resultado de seu tempo, do universo de ideias que as cercam. O texto literário é composto de imagens e conceitos que pertencem ao mundo real que abrange a realidade de sua produção. É preciso antes de qualquer tipo de análise ou perceção acerca de um texto literário, entender como ele se constrói como texto literário. Segundo Antoine Compagnon em O Demônio da Teoria,

Os estudos literários falam da literatura das mais diferentes maneiras, concordam, entretanto, num ponto: de todo estudo literário, qualquer seja o seu objetivo, a primeira questão a ser colocada embora pouco teórica, é a da definição que ele fornece (ou não) de seu objeto: o texto literário. O que torna esse texto literário? Ou como ele define as qualidades literárias do texto literário? (2001, p. 29)

Gonçalo M Tavares (1970), tem uma vasta produção literária, é ganhador de inúmeros prêmios: Prêmio revelação da Associação Portuguesa de Escritores, Grande Prêmio de conto Camilo Castelo Branco, Prêmio Ler/Millenium BCP e Prêmio José Saramago. Diversificada em gêneros textuais e temas sua obra é referência na produção portuguesa contemporânea. E traduzido em todo o mundo.

Entre as suas obras mais conhecidas está Jerusalém (Edição de 2010, Leya/ Caminho), romance que compõe a tetralogia ou os Livros negros como são chamados, devido a temática que os constituem: a dor, a solidão, a guerra, o holocausto.

Jerusalém é a história de um grupo de personagens que coaabitam uma mesma cidade, sem nome, mas que carrega em si a história do holocausto, as marcas da guerra em corpos e mentes. As personagens trazem em si a loucura como elo que os une em torno da dor.

As personagens que compõem a narrativa são indivíduos marcados por algum distúrbio psíquico, traumas e perturbações causados por memórias numa constante catarse do coletivo, da dor sentida por outros que antes deles ou até ao mesmo tempo experienciaram a mesma dor: Mylia, Ernest, Theodor Busbeck, e Kaas, Hanna e Hinnerk. O cruzamento das histórias particulares, o entrelaçamento de seus motivos, das razões de cada movimento das personagens, vão se delineando, se constituindo ao longo da escrita de Gonçalo M. Tavares. A circularidade da existência e do destino de cada uma dessas figuras, partindo da imaginação de seu autor, desdobra-se em reflexão e memória. Uma escritura da experiência, da dor, do questionamento sobre o devir histórico e da própria relação do sujeito com as suas histórias singulares. 


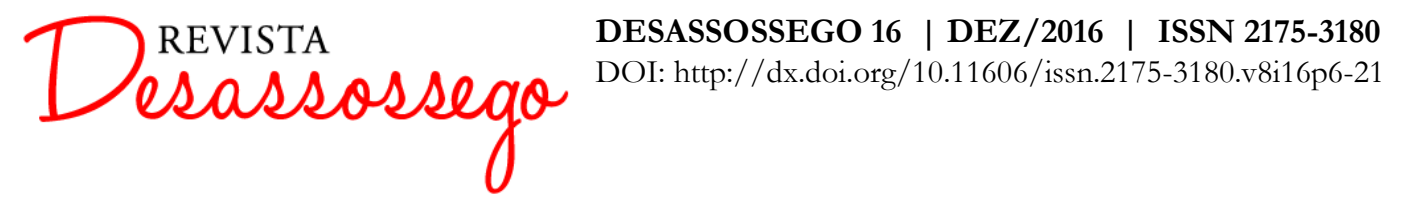

A história se passa numa cidade pequena e sem nome, com lugares demarcados como a casa de Mylia, a casa de Busbeck, de Hanna, de Ernest e o Hospício Georg Rosenberg, as ruas, as praças os locais por onde essas personagens transitam e experienciam suas sensações e vidas não recebem nomes ou caracterizações, são apenas locais, numa ideia de não-lugar, mas de pertença, de enraizamento da própria dor dessas personagens que compõem esse cenário.

A loucura é resgatada em Jerusalém como uma forma de entender e perceber os oprimidos, os esquecidos, os marginalizados pela guerra, pelo holocausto, pela sociedade e as suas formas de exclusão. A crueldade ontológica, exposta através das relações das personagens umas com as outras, os processos científicos e da própria manutenção de uma memória construída sobre a guerra e sob a égide da dor ("Dor, pensou, a dor era uma palavra essencial." (TAVARES, 2010, p.7), formam o tecido que une os destinos de todas numa mesma cidade, num mesmo momento. O narrador de Jerusalém se debruça sobre os corpos das personagens, anatomiza suas dores e as marcas que esses corpos tem, como num mapeamento da memória que os compõe.

A boneca de Kokoschka romance de Afonso Cruz (1971) tem como motivo a história de Oskar Kokoschka, pintor austríaco que apaixonado de maneira intensa pela amante, a compositora e artista plástica, Alma Mahler, manda construir uma boneca ${ }^{4}$ à sua semelhança para suprir sua ausência, quando ela decide deixá-lo. A loucura de Oskar, ou melhor sua obsessão pela artista o levou a acreditar que a suposta boneca era a personificação da presença da amante, sem preocupar-se com a sociedade ou os comentários, o pintor saía com a boneca em público, sendo ela sua companhia em diversos eventos. Cansado da companheira inanimada, farto de sua mudez e imobilidade, ele quebra-lhe uma garrafa de vinho na cabeça e a dispensa no lixo.

A narrativa é dividida em três partes. A primeira que dá início e nos situa sobre a origem do motivo, passa-se em Dresden ${ }^{5}$, Alemanha, durante a Segunda Guerra Mundial. Dresden é o ponto de partida da história. É protagonizada por Isaac Dresner e Bonifaz Vogel, dono de uma loja de pássaros. É da cave de sua loja que uma voz emerge como que do mundo sobrenatural. Ao ponto de supor que estava maluco ou assombrado, descobre que a voz é de Isaac, um garoto judeu, que refugia-se ali por conta da guerra e da

\footnotetext{
${ }^{4}$ Mito de Pigmalião e Galatéia. Segundo a mitologia, Pigmalião idealizou a mulher perfeita na construção de uma estátua, Galatéia, a quem os deuses deram vida.

${ }^{5}$ Dresden foi bombardeada de forma terrível (pela primeira vez foram usadas bombas de deflagração de fósforo) durante a Segunda Guerra Mundial e cerca de 35 mil pessoas morreram.
} 


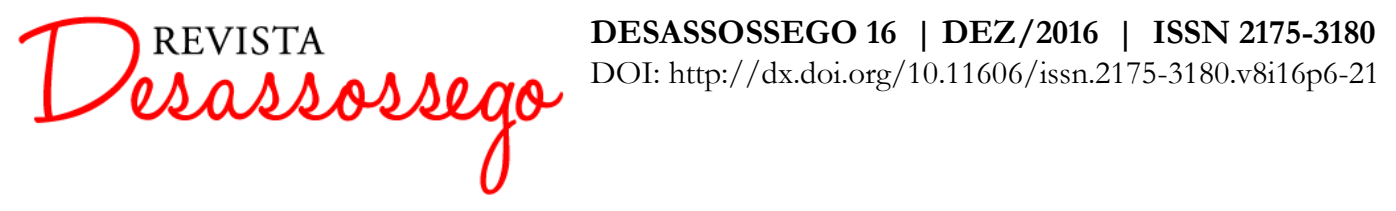

perseguição: "o pequeno - invisível - judeu passou a viver naquela cave escura, debaixo do soalho e passou a ser apenas uma voz".

A segunda parte passa-se em Paris, no período pós-guerra. Isaac é agora um homem casado, que vive com a esposa e o Senhor Vogel. A esposa é Tsilia Kacev, uma pintora encontrada no meio da rua em Dresner. É dono de uma pequena editora, Euridice! Euridice!, e de uma livraria, a Humilhados e Ofendidos ${ }^{6}$ (também pequena e que voltava-se sobre os escritores que não tinham sucesso). E no seu trabalho de editor, acaba conhecendo a história de um escritor que nunca conseguiu resultados positivos com a sua literatura. Mathias Popa, um fracassado que, mesmo tendo roubado os manuscritos de Thomas Mann, não obtém sucesso de nenhum jeito. Interessado pela ideia, contata o escritor revelando o interesse em publicar suas obras. A boneca de Oskar Kokoschka começa a tomar vida novamente, agora em palavras. A história do escritor é sobre a família Varga. Sobre sua origem, sobre a vida antes, durante e depois da guerra. Mathias que sustenta a ideia de que a sua vocação é a espera, passara a vida esperando por um editor que se interessasse por sua obra. Segundo ele "Não existe mentira na literatura, na ficção" (CRUZ, 2014, p. 83) e não existe também verdade na vida real, daí desdobram-se e entrelaçam-se as histórias.

Mathias traz consigo a densidade das palavras, Bonifaz o medo do amor, Isaac a memória e Tsilia o silêncio das cores. $\mathrm{Na}$ arquitetura de suas existências é que a literatura de Afonso Cruz se constrói: ao ligar as personagens a morte e a vida, a sobrevivência e a necessidade é que elas surgem como seres habitantes de um mundo real e não apenas literário. Narrativa dentro da narrativa, num processo de mise-en-abyme ${ }^{7}, A$ boneca de Kokoschka está inserida dentro da segunda parte da obra de Afonso Cruz. Mathias Popa, contava como, na verdade, ele se tinha originado e de onde vinha.

A terceira parte do romance de Afonso Cruz traz a história de Miro Korda, ou ainda Ramiro Corda, músico de jazz, português que qualificava as pessoas com notas musicais: "Korda classificava as pessoas por acordes musicais. Andava na rua a atribuir acordes musicais às pessoas que se cruzavam com ele"(CRUZ, 2014,p.184).

\footnotetext{
${ }^{6}$ Romance de Dostoiéviski, publicado em 1861. A narrativa tem como tema a luta de classes, a resistência a hipocrisia social e o cotidiano sofrido e miserável de uma família na cidade grande.

${ }^{7}$ Segundo Carlos Reis e Ana Cristina Moreira Lopes em Dicionário de narratologia, é um recurso que aparenta "como se projetasse em profundidade uma representação reduzida, ligeiramente alterada ou figurada da história em seu curso ou do seu desfecho” (2011, p.233).
} 


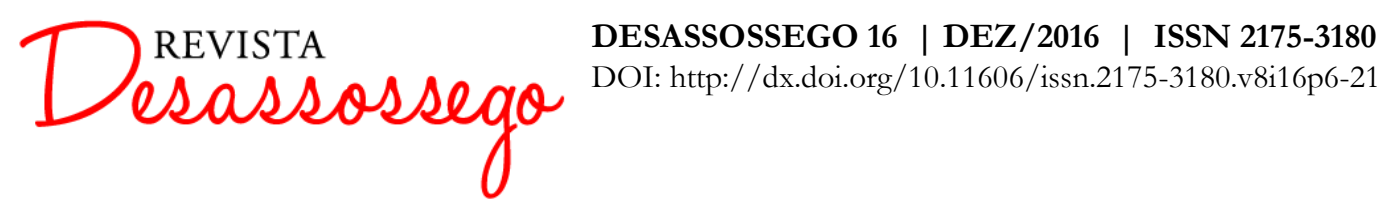

A narrativa de Afonso Cruz é um percurso ficcional que embriona-se na arte, em diversas artes: a arte de tratar a matéria dando-lhe vida, cor, aspecto e sentimento; a arte de contar histórias, de escrevê-las, engendrá-las em cada palavra escrita ou falada; a arte de produzir a música e provocar no espírito humano as mais diferentes emoções; a arte de morrer e de permanecer e sobretudo a arte de permanecer e construir-se até mesmo nos tempos de guerra e cinzas.

No meu peito já não cabem pássaros é o livro de estreia de Nuno Camarneiro (1977). Construído de forma fragmentada e alternada em sua organização capitular, o romance é o encontro de três histórias de personagens diferentes orientadas por apenas um fato: a passagem do cometa $\mathrm{Halley}^{8}$, pelos céus, no ano de $1910^{9}$. Anunciado como o fim do mundo, o trânsito do cometa no espaço, visível da Terra, causou imensa confusão entre as pessoas de diversas partes do mundo: crucificações, suicídios, enlouquecimento ou ainda a resignação e o silêncio melancólico que marcava a espera do fim.

Publicado pela primeira vez em 2011, a narrativa construída por Nuno Camarneiro se divide em cinco partes: "Exórdio", "Confronto", "Acerto", “Assombro" e "Fecho”. Os capítulos que compõem cada parte vão delinear justamente sobre o sentido de cada nome das partes.

Através das cinco partes as personagens vão aos poucos se revelando e revelando suas narrativas particulares. Começamos por $\mathrm{Karl}^{10}$, um estrangeiro que sobrevive ou tenta fazê-lo na grande Nova Iorque. É lavador de janelas nos grandes prédios da cidade moderna e engolidora das vidas mais simples:" Dois homens pendurados por arneses a oitenta metros de altura. Os que trabalham dentro chamam-lhes pardais com uma ironia desnecessária. Quarenta e oito horas semanais de equilibrismo pagas a quatro dólares, um bom emprego para quem acaba de chegar a cidade." (CAMARNEIRO, 2011, p. 13). Imigrante, sozinho e desconhecendo os mecanismos da sociedade em que agora estava tentando se inserir Karl estava a mercê não apenas da altura dos andaimes e da distância entre eles e o chão, mas também das pessoas e suas lógicas pessoais e íntimas de sobrevivência.

\footnotetext{
${ }^{8}$ O cometa Halley passou pela Terra em 1910, acreditava-se que ele emitia gases venenosos e que seria o fim da humanidade.

${ }^{9} \mathrm{O}$ início do romance apresenta jornais da época que comentam a notícia da passagens dos cometas.

10 Personagem do romance inacabado de Franz Kafka, Desaparecido ou Amérika.
} 


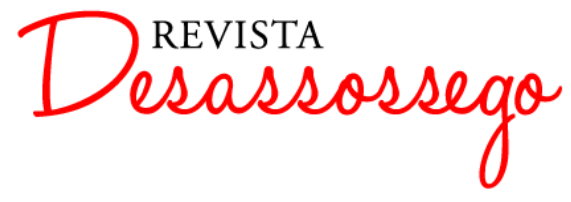

DESASSOSSEGO 16 | DEZ/2016 | ISSN 2175-3180

DOI: http://dx.doi.org/10.11606/issn.2175-3180.v8i16p6-21

A segunda história é de Jorge ${ }^{11}$, um garoto argentino que, vivendo cercado pela família, pela literatura e pelas histórias criadas por uma imaginação prodigiosa, tem de aprender a conviver no ambiente escolar, tão rico em diferenças, e, para Jorge, tão pobre enquanto espaço de imaginação e acolhimento. Jorge é ainda é um menino quando revela sua capacidade imaginativa, sua habilidade franca e incomensurável de criar histórias, de refugiar-se nelas. Numa cidade da América Latina - Sueson Birea, Eusson Birea, Euason Bires, Eusanor Bines, Eusaor Nibes, Auseor Nibes, Auseor Bines, Suseor Binea, Suseor Aineb, Auseor Sineb, Aureos Sineb, Auneos Sireb, Suneos Aireb ${ }^{12}$ e Buenos Aires - numa casa num bairro distante, cercado pela imaginação e pela proteção do espírito familiar, Jorge Luís Borges, o pequeno e arredio garoto Jorge criado por Nuno Camarneiro é a figura do escritor argentino e sua possível infância.

A terceira história é a de Fernando ${ }^{13}$, que chega a Lisboa num navio. Sua travessia pelo Atlântico o levará a cidade antiga de sua vida e à casa da tia, onde irá morar. . Assolado pela febre, Fernando ao ser tratado pelas tias e médico e, receber a extrema unção do padre, dá-se conta que a febre está escondida em seu espírito, em desejos colados ao corpo, numa insatisfação ou incompletude que o transforma dia-a-dia, numa inquietude que representa sua inabilidade em adaptar-se a nova vida. Um jovem que não gosta de conviver com os demais de sua idade, não acredita no amor e multiplica-se nos poemas que escreve. Apaixona-se por uma mulher misteriosa perde um tanto de si e da sua poesia nesse amor.

\section{Considerações finais}

Ao pensarmos essas obras como representantes da novíssima literatura portuguesa, não as aproximamos pela faixa etária de seus autores, colocando-os sob a denominação de uma geração $X$. Ela se explica como novíssima por localizar-se de uma maneira diferente quando pensamos em literatura portuguesa. Ao pensarmos seus contextos de produção: um mundo que revê seus conceitos de fronteira, de cultura, de identidade e num constante processo de determinadas nações como um reposicionamento pós-guerra, póscolonialismo, conseguimos identificar o que se coloca sob a égide de uma nova literatura portuguesa.

\footnotetext{
11 Jorge Luís Borges (1889-1986), escritor argentino.

12 Anagrama de Buenos Aires, cidade de origem de Jorge Luís Borges, a criação de Nuno Camarneiro remete a criatividade Borges, a sua capacidade de inventar animais e lugares.

${ }^{13}$ Fernando Pessoa (1888-1935). Escritor português.
} 


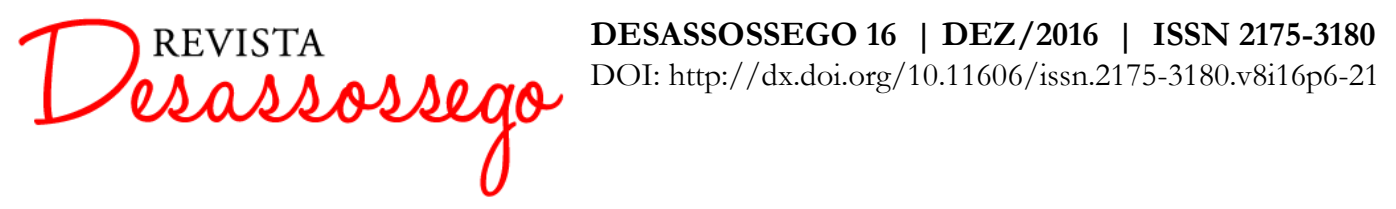

Ao repensar o holocausto, a brutalidade, a violência, a dor, a doenças psíquicas, colocando em suas personagens a materialidade da história, a memória de um tempo recente, conjugado com a loucura e a necessidade do sempre buscar o outro como forma de montagem de um quebra-cabeças de si mesmo, Gonçalo M Tavares torna-se um dos grandes nomes dessa literatura-mundo que se dispõe a nossa leitura.

As personagens que o autor constrói em Jerusalém não possuem um território-nação, mas estão num entre-lugar no mundo, ocupado pela loucura, pela demência e pela amargura de um passado marcado pela destruição e pela dor. A violência exercida na guerra, a mutilação de corpos, ideais e futuros é o que demarca as características da narrativa. A condição humana, a trama de suas relações, as estruturas sociais e o modo como o ente se relaciona como o mundo são os fios que compõem a urdidura imbrincada de suas histórias. Suas personagens são atormentadas pela própria existência e pela dicotomia de vida e morte, mimese do mundo real.

Num espaço não determinado, mas ambientado principalmente como um sistema de ruas, um hospício, uma igreja, esses destinos marcados se cruzam, entremeiam-se, conjugam-se na igualdade da loucura, ainda que cada uma corresponda a um tipo de manifestação. Esquizofrenia, obsessão, depressão, deficiências mentais e físicas, aliam-se ao desejo que somente a alteridade oferece como resposta: o conhecimento e aproximação do outro.

Afonso Cruz, em A boneca de Kokoschka, também retoma o trauma da guerra, a dor, a solidão, o medo da morte. A perseguição dos judeus na Segunda Grande Guerra e todos os desdobramentos que a infelicidade da guerra causou na vida de muitas pessoas. Em sua narrativa alternam-se temas como a solidão e o abandono, mas também a importância da arte, da música e da solidariedade. Suas personagens constroem um universo mimético em que a circularidade labirintica os aproxima e afirma que todas as causas e efeitos estão ligadas diretamente a um único motivo.

A necessidade de compreender o outro, de compreender sua origem, de conhecer a si mesmo e a própria memória percorrem a narrativa de Afonso Cruz. Uma história desencadeada a partir da criação de uma boneca para suprir a existência de uma mulher. Laços afetivos, desencontros, esperanças, amizades e, relações amorosas e paixões surgiram do momento em que o amante cansado da boneca joga-a no lixo. Do mundo e no mundo a boneca comunica e liga diversas personagens. 


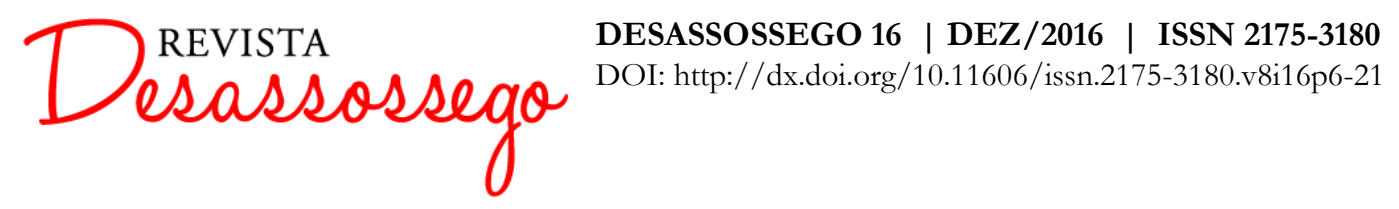

Essas relações entre as personagens se dão através de um "atavismo histórico", como se a boneca os tornasse indissociáveis. Orhan Pamuk, em $O$ romancista ingênuo e o sentimental, comenta-nos sobre a personagem e sua relação com o mundo:

Visto pelos olhos de suas personagens, o mundo do romance nos parece mais próximo e mais compreensível. É essa proximidade que empresta a arte do romance seu poder irresistível. No entanto, o foco primário não é a personalidade e a moralidade das personagens principais, mas a natureza de seu mundo. A vida dos protagonistas, seu lugar no mundo, a maneira como se sentem, veem e lidam com o seu mundo - esse é o tema do romance literário. (PAMUK, 2011, p. 47)

O grande tema do romance de Afonso é a memória, a construção da memória e das relações que dela emergem. O poder da literatura como escrita da memória e da identidade. Sobretudo, a partir dessa memória também a possibilidade da esperança. Novas construções de sujeitos a partir da alteridade, do compreender-se no mundo como parte de uma potente e interligada rede de relações de memória, passados e que se desenvolverão em futuros possíveis.

A questão labiríntica e que nos coloca sempre próximo do outro também aparece em Nuno Camarneiro no romance No meu peito já não cabem pássaros. A história de três personagens com localizações completamente diferentes, Lisboa, Buenos Aires e Nova Iorque, com idades diferentes e nacionalidades diferentes, mas que passam pelo mesmo evento: a passagem do cometa Halley pelos céus no ano de 1910.

Cada trauma vivido, cada necessidade, configura-se como elemento que constrói a memória e o futuro dessas personagens: o desejo de uma vida melhor, a possibilidade de um universo ficcional qie transponha o sonho e a identidade além da materialidade do indivíduo. Numa escolha narrativa de intertextualidade, Nuno Camarneiro retoma personagens ficcionais como o Karl de Kafka em Amérika, Jorge Luís Borges e Fernando Pessoa. Apoiada no imaginário literário e extraliterário, sua obra trabalha sobretudo com as questões da existência humana, de uma personagem a outra, ele nos mostra os infortúnios do homem em relação à fatalidade.

Beatriz Sarlo, em Tempo Passado, Cultura da memória e guinada subjetiva, comenta que o passado é sempre conflituoso (2007, p.9). Por que pensar o passado é permitir acreditar na memória, e que essa tem que acreditar na reconstituição do que aconteceu. Assim, nas narrativas desses três autores, o que se manifesta em suas ficções é justamente uma modalidade de perceber e reconstruir o passado. Entender o que os homens herdaram da 


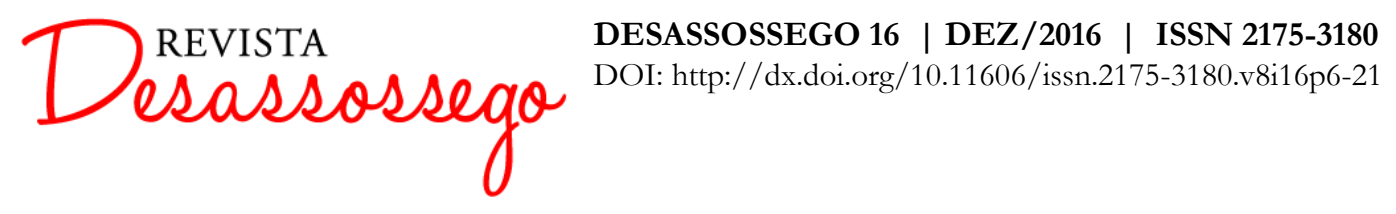

guerra (Jerusalém); partilhar o que homens sentiram durante a guerra e em diferentes condições (A boneca de Kokoschkea) e ainda entender como um sujeito histórico pode ser também um sujeito ficcional, e que dentro dessa narrativa ele se iguala aos homens do seu tempo, ainda que ele também tenha a função de criador de possíveis ficções (No men peito já não cabem pássaros).

Construções diferentes em seus aspectos constitutivos, essas obras compõem uma nova perspectiva da literatura portuguesa. Vão além do sujeito português, expandem-se para fora das fronteiras culturais e identitárias da cultura portuguesa. Configuram-se como uma nova visão do sujeito português, não através da representação de personagens que tragam em sua constituição traços típicos de identidade, mas pela forma como tratam a memória cultural pertencente ao mundo todo. Como expandem e também tomam para si uma nova percepção de sujeito e memória.

Esses autores rompem com a questão de narrar apenas dentro da identidade cultural a que estão associados, ao mesmo tempo alicerçam uma nova concepção do seu papel de inventor/criador de universos ficcionais. O espaço ficcional é, por sua natureza, o espaço das possibilidades. Além das fronteiras ficcionais, rompem com formas de narrar, com construções de personagens, com a história do mundo e dos homens. Formam um novo cânone marcado pela diversidade, elemento intrínseco do novo modo de pensar o sujeito contemporâneo.

Assim, determinado como contemporâneo ${ }^{14}$, como novíssimo, esse recente modo de perceber o sujeito, que é engendrado dentro da cultura, aqui nomeadamente, a literatura, portuguesa, é de fato uma nova forma de ver o homem português. Um habitante do entrelugar que a história oferece, um observador do mundo que o compõe e sobretudo um artista que reflete nas suas tintas o que prescinde da natureza humana em diversos tempos históricos e num movimento externo e progressivo de saída do seu território identitário de nação e de referência cultural.

\section{Referências}

BHABHA. Homi. O local da cultura. Tradução de Myriam Ávila, Eliana Lourenço de Lima Reis e Glaucia Renata Gonçalves. Belo Horizonte: UFMG, 1998.

14 Patrícia Infante da Câmara, no Centro de Estudos Comparatistas da Faculdade de Letras da Universidade de Lisboa, iniciou em 2015 a sua pesquisa de doutorado no âmbito da Literatura Portuguesa Contemporânea à luz do conceito de Literatura-Mundo, desenvolvendo desde então trabalho sobre os autores mencionados neste artigo. 


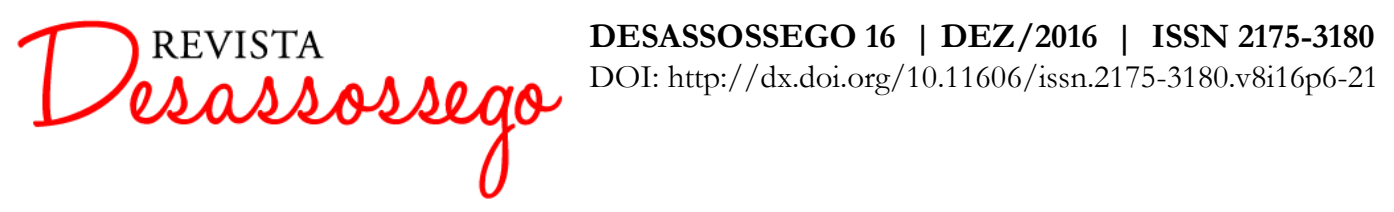

BUESCU, Helena Carvalhão. Experiência do incomum e boa vizinhança: literatura comparada $e$ literatura mundo. Porto: Porto Editora, 2013.

CANDIDO. Literatura e Sociedade - estudos de teoria e história literária. São Paulo: T-A. Editor, 2000.

CAMARNEIRO, Nuno. No meu peito já não cabem pássaros. Lisboa: Leya Dom Quixote, 2011. COMPAGNON. Antoine. O demônio da teoria: literatura e senso comum. Tradução de Cleonice Paes Barreto Mourão. Consuelo Fortes Santiago. Belo Horizonte: UFMG, 2009.

CRUZ, Afonso. A boneca de Kokoschka. Lisboa: Quetzal, 2014.

ECO, Umberto. Confissões de um jovem romancista. São Paulo: Cosac\&Naify, 2013.

LOURENÇO, Eduardo. O labirinto da saudade. Lisboa: Gradiva, 2015.

PAMUK, Orhan. O romancista ingênuo e o sentimental. São Paulo: Companhia das Letras, 2011.

SARLO, Beatriz. Tempo Passado, Cultura da memória e guinada subjetiva. Tradução de Rosa Freire de Aguiar. São Paulo: Companhia das Letras - UFMG, 2007.

TAVARES, Gonçalo M. Jerusalém. Lisboa: Editorial Caminho,2010.

TODOROV, Tvetzan. A literatura em perigo. São Paulo: Difel, 2009. 